\title{
Towards an ecosystem approach to fisheries management (EAFM) when trawl surveys provide the main source of information
}

\author{
John Cotter ${ }^{1}$, Pierre Petitgas ${ }^{2}$, Alvaro Abella ${ }^{3}$, Panayiota Apostolaki ${ }^{1}$, Benoit Mesnil ${ }^{2}$, \\ Chrissi-Yianna Politou ${ }^{4}$, Jacques Rivoirard ${ }^{5}$, Marie-Joëlle Rochet ${ }^{2}$, Maria Teresa Spedicato ${ }^{6}$, \\ Verena M. Trenkel ${ }^{2}$ and Mathieu Woillez ${ }^{5, a}$ \\ CEFAS, Lowestoft, NR33 0HT, UK \\ 2 IFREMER, Département EMH, BP 21105, 44311 Nantes, France \\ 3 ARPAT Agenzia Regionale per la Protezione Ambientale della Toscana, Via Marradi 114, 57100 Livorno, Italy \\ ${ }^{4}$ Hellenic Centre for Marine Research, Institute of Marine Biological Resources, Aghios Kosmas, Hellinikon, Athens 16604, Greece \\ 5 Mines-ParisTech, Centre de Géosciences/Géostatistique, 35 rue St Honoré, 77300 Fontainebleau, France \\ ${ }^{6}$ COISPA Tecnologia \& Ricerca, Via dei Trulli, 18/20, 70045 Torre a Mare, Bari, Italy
}

Received 8 September 2008; Accepted 25 March 2009

\begin{abstract}
Ideas and considerations are put forward for managing fisheries and marine populations using primarily trawl surveys to supply biological and spatial indicators of the state of stocks, and to permit catch per unit effort (CPUE)-based assessments. Trawl surveys seldom allow absolute estimates of fish population sizes but, if appropriately located, timed, and designed, can provide a broad range of information about catchable fish species and the ecosystem that supports them. This information may be more conducive to sustainable management of fisheries than the traditional focus on the abundances of selected stocks. The paper first briefly proposes how survey-based methods might supplement existing fishery-dependent stock assessments, as would be necessary during a transition phase to a more ecosystem-orientated system of management. Full survey-based management is then considered in relation to management objectives, the selection of indicators, survey design, reference periods, levels and directions, statistical aspects, CPUE-based assessments, and management responses to good and bad signals from the ecosystem. We argue that existing fishery-dependent stock assessments cannot be claimed to produce absolute estimates of stock abundance and fishing mortality because natural mortality (M) is seldom known accurately and, therefore, that they should not be presumed superior to the relative information from surveys, and an agreeable form of adaptive management.
\end{abstract}

Key words: Fisheries management / Trawl survey / State indicator / Spatial indicator / Survey-based stock assessment / Fisheries-independent assessment / Fishing effort indicator

\section{Introduction}

Official landings statistics have formed the primary basis of fish stock assessments for many years even though, in Europe, there are long-standing criticisms of their adequacy for the purpose (Anonymous 1986). Problems arise because:

- fishing is a commercial operation, not a scientific sampling survey;

- fishers are adept at finding fishable concentrations of fish even when stocks are low (Rose and Kulka 1999);

- fishing efficiencies vary over time (Marchal et al. 2003; Marchal et al. 2007);

- landings do not include fish discarded at sea; and

- there are considerable incentives for fishers to miss-declare their landings.

\footnotetext{
a Corresponding author: john.cotter@fishworldscience.com
}

For these reasons, attention has been turning towards scientifically conducted trawl surveys as alternative, more dependable sources of information about fish stocks (Cook 1997; Porch et al. 2006; Trenkel 2008). In the Mediterranean, monitoring of landings was sparse at least until 2002 (when the EC data collection regulation was applied) and fish surveys have for many years served as the primary assessment tool (Abella et al. 1999). More generally, trawl surveys can provide information about many non-commercial species and therefore, potentially, about the health of the overall marine ecosystem.

The need to move away from the management of singlespecies and towards management of whole ecosystems, the so-called "ecosystem approach to fisheries management" (EAFM), also known as "ecosystem-based management", is now accepted by many scientists (Rice et al. 2005), nongovernmental (Ward et al. 2006), and governmental organisations (EC 2001a; FAO 2003). Garcia and Cochrane (2005) 
summarise the international political development of EAFM. Since so many fisheries are over-fished (EC 2001b; Jackson et al. 2001; Pauly et al. 2002; Myers and Worm 2003; Mullon et al. 2005), the hope is that EAFM can take us closer to sustainable exploitation of commercial fisheries without undesirable environmental side effects, such as trophic cascades and regime shifts (Daskalov et al. 2007; Daskalov 2008). Trawl surveys, by providing data about a wide range of species, appear to offer a valuable scientific tool for implementing an EAFM.

Trawl surveys can be carried out by research vessels, specially chartered fishing vessels, or commercial vessels operated in partnership with scientists (Armstrong et al. 2008). The essential feature of a survey is that trawling be carried out in a fully standardised way within a bounded region occupied by the stocks of interest. A small mesh liner is often fitted within the codend of a survey trawl to try to equalise the catching rates for different sizes of fish. The relative catch rates of a species from time to time and place to place are then intended to indicate approximate relative abundances of that species. The relative abundances of different species, on the other hand, cannot be so estimated from a trawl survey unless their relative catch rates are known - which is seldom the case though approximations may be assumed. The standardisation of trawl surveys must be carried out with great care and may involve intercalibrations of vessels or gear. See Anonymous (2004, 2005, 2006); for statistical aspects, see Kimura and Somerton (2006), and for problems associated with the noise made by survey vessels, see Mitson (1995) and Mitson and Knudsen (2003).

Much general and technical advice on the practical implementation of an EAFM is now available (FAO 2003; Lack 2004; Link 2005; Ward et al. 2006; Grieve and Short 2007; McShane et al. 2007). The present paper offers advice on how trawl surveys might be used for EAFM when they form the primary source of information. It summarises the research findings of a recent European project, entitled "Fishery-independent, survey-based, operational assessment techniques" (FISBOAT) in the context of other published results. The intention is to draw attention to some of the many benefits and complications of using trawl surveys to support an EAFM. The paper does not attempt a wide-ranging literature review because of others already available (Jennings and Kaiser 1998; Rochet and Trenkel 2003; Jennings 2005; Rochet and Trenkel 2009). It also does not review specific fisheries or ecosystems because each is likely to be different and to need specialist knowledge, judging from case studies carried out under this European project and, in the global context, by world wide fund (WWF) (Grieve and Short 2007). Our approach is strongly influenced by our familiarity with European marine fisheries where trawl surveys already contribute important information to stock assessments, most of which use fishery-dependent data (e.g. from market sampling, observer surveys) as well. Lastly, our emphasis on trawl surveys is not intended to imply that fishery-dependent data are necessarily inferior (Cotter and Pilling 2007), or that other types of scientific survey, e.g. acoustic surveys, are not useful for EAFM purposes.

Our paper is structured according to the likely ordering of practical tasks for designing an EAFM for a particular fishery.
Because single-species, abundance-related, fishery-dependent stock assessments form the main scientific support for the management system prevailing in Europe and elsewhere at the time of writing, we first briefly discuss aspects of the crucial transition phase to an EAFM (Sect. 2). Then consider EAFM and trawl surveys with little further reference to existing assessment practices (3). Each sub-section deals with a necessary stage of implementation. The preliminary planning stage (3.1) involves consideration of the management and decisionmaking structures, the choice of state and pressure indicators to use, and whether or not the available trawl survey(s) will be adequate for the job of monitoring state indicators. The next stage (3.2) concerns data analysis, CPUE modelling, and comparisons with reference levels or trends, as will be needed to convert survey results into management guidance. The last, decision-making stage (3.3) concerns the options for managerial responses to good and bad stock indications. We conclude the article with a short discussion of some of the issues raised.

\section{Transition from abundance-based stock assessments to a survey-based EAFM}

The abundance of fish, as conventionally estimated with many existing methods of stock assessment, is only one aspect of the viability of the population. Poor viability may be indicated by poor growth, weak or delayed gonad development or atresia, or by low numbers of mature fish. Biological indicators for assessing size, growth, and reproduction from trawl surveys are shown in Table 1 (see also Cotter et al. 2009). Poor viability may also be indicated by atypical spatial distributions attributable to unfavourable environmental factors or competition with other species. Spatial indicators of distributional characteristics applicable to station-by-station data from trawl surveys can be found in Table 2 (see also Woillez et al. 2007). For these reasons, augmentation of existing abundancebased stock assessments with the results of monitoring biological and spatial indicators is recommended when a suitable trawl survey is available. It must, however, be done with care to minimise the spurious statistical relationships that can arise if data are used twice (Cotter et al. 2004), for example if indicators use CPUE data that are also used to tune an assessment model such as exploratory extended survivors analysis (XSA). If such traps are avoided, parallel use of biological and spatial indicators alongside stock abundance assessments should aid a smooth and secure transition between existing single-species assessments and a future EAFM that relies more heavily on indicators.

The opportunity also exists to fit one or more of the CPUEbased models listed in Table 4 to survey data (Mesnil et al. 2009) as support for current, landings- and catch-based methods of stock assessment. As with indicators, the validity of a separate analysis with the chosen surveys depends on whether or not they were also used to tune the main assessment model. Given that they were not, or that the dependence is known to be weak, the obvious application of CPUE modelling is for a comparison of estimates of parameters made by both methods such as the coefficient of total mortality, $Z$, and the relative sizes of recruiting year classes. Alternatively, if the surveys 
Table 1. Biological population indicators considered under the FISBOAT project (Cotter et al. 2009).

\begin{tabular}{lll}
\hline Indicator & Abbreviation & Description and properties \\
\hline $\begin{array}{l}\text { Abundance-based } \\
\text { Log abundance \& Intrinsic }\end{array}$ & $\log (N), r$ & $\begin{array}{l}r \text { is slope of log } N \text { (all ages) over time. Useful when length and age compositions } \\
\text { population growth rate }\end{array}$ \\
& $\begin{array}{l}\text { are not available. } r \text { decreases with fishing particularly if recruitment is also af- } \\
\text { fected. Other factors could also cause a decline. Log } N \text { and } r \text { must be interpreted } \\
\text { together. }\end{array}$
\end{tabular}

Total mortality $\quad Z \quad Z \quad Z$ measures decline of log abundance in a year class. Increases with fishing, or net migration out of the survey area.

\begin{tabular}{|c|c|c|}
\hline \multicolumn{3}{|l|}{ Size- and age-based } \\
\hline $\begin{array}{l}\text { Numbers-at-length, numbers- } \\
\text { at-age, length statistics }\end{array}$ & NaL, NaA, Lbar, L5O & $\begin{array}{l}\text { Length- or age-frequency distributions. Lack of large or old fish may indicate } \\
\text { over-fishing, low productivity economically, and vulnerability to high fishing } \\
\text { pressures. Also affected by recruitment. }\end{array}$ \\
\hline \multicolumn{3}{|l|}{ Weight-based } \\
\hline Catch weight per station & WPUE & $\begin{array}{l}\text { Total weight per unit effort of one (or more) species. Relates to stock biomass and } \\
\text { size composition. Affected by seasonal growth and spawning. Less influenced by } \\
\text { recruitments than length statistics. }\end{array}$ \\
\hline Condition & $C$ & $\begin{array}{l}\text { Average body weight for a given body size. Reflects nutritional status and repro- } \\
\text { ductive fitness. Affected by season and gender. }\end{array}$ \\
\hline \multicolumn{3}{|l|}{ Reproductive } \\
\hline Spawning stock in number & $S S N$ & $\begin{array}{l}\text { Number of mature fish per unit effort. Low } S S N \text { implies vulnerability to interfer- } \\
\text { ence with reproductive processes, and high fishing pressures. Requires accurate } \\
\text { maturity staging, and surveys in the pre-spawning season. }\end{array}$ \\
\hline Gonadosomatic index & $G S I$ & $\begin{array}{l}\text { The ratio of gonad weight to body weight. Affected by nutritional status, maturity } \\
\text { stage, and reproductive fitness. Requires weighings but not maturity stages unlike } \\
\text { other reproductive indicators. Requires seasonally timed surveys. }\end{array}$ \\
\hline Length and age at maturity & LaM50, AaM50 & $\begin{array}{l}\text { Length or age at which } 50 \% \text { of the individuals in a fish stock are reproductively } \\
\text { mature. Can decrease slowly with fishing. Also varies widely with latitude. Re- } \\
\text { quires accurate maturity staging and seasonally timed surveys. }\end{array}$ \\
\hline
\end{tabular}

were fully utilised to tune the assessment, a comparison of estimates might still be useful for finding and diagnosing any modelling problems in the assessment. Other possibilities for CPUE modelling with survey results may be opened up by the relative simplicity of some methods, making them easier to illustrate and explain to non-specialists on the stock management committee. They might also be applied to screen CPUE data before use in the assessment, or to examine surveys rejected for tuning purposes or that are giving contrary results.

Simulation tools can also be useful for checking the validity of assessments and management methods. The ALADYM (Lembo et al. 2009) and FLR (fisheries library in the R statistical language) simulation systems (Kell et al. 2007; Hillary 2009) are both based on simulating an underlying biological population (using the "operating model") which can be subjected to different harvest control rules (HCRs) (Apostolaki and Hillary 2009) to try to find a way to manage the fishery sustainably. Variants of the HCRs can be formulated and tested using the responses of abundance indices obtained from trawl surveys. For example, last year's total allowable catches (TAC) might be increased if preceding abundance indices showed a trend upwards. FLR also allows the robustness of HCRs to be tested when errors and biases are present in the indices or in other information about the stock, when the underlying population dynamics are mis-specified, or when the HCR is not complied with. Testing of different types of HCRs, e.g. protecting juveniles, area closures, etc., might also be possible though neither FLR nor ALADYM currently permit geographic variability. Other, more elaborate simulators may be useful for such tasks, e.g. ATLANTIS at http://atlantis.cmar. csiro.au/ (Fulton et al. 2003).

\section{Towards EAFM using trawl survey data only}

\subsection{Planning stage}

\section{Management and objectives}

We assume that a committee of some sort exists for managing the fishery. Political and organisational options for this body are discussed fully in the collection of papers resulting from the EC EFIMAS project (Motos and Wilson 2006). 
Table 2. Spatial population indicators considered under the FISBOAT project (Woillez et al. 2009a).

\begin{tabular}{|c|c|c|}
\hline Indicator & Abbreviation & Description and properties \\
\hline Centre of gravity & $C G$ & Mean location of the individuals of a population. $C G$ is sensitive to high densities of fish. \\
\hline Inertia & $I$ & $\begin{array}{l}\text { Variance of the location of the individuals of a population. Indicates dispersal but is sen- } \\
\text { sitive to high densities of fish. }\end{array}$ \\
\hline Anisotropy, Isotropy & An, Is & $\begin{array}{l}\text { Anisotropy measures the elongation of the spatial distribution of the population. Isotropy } \\
\text { is the inverse. Can be affected by the appearance or disappearance of patches of fish. }\end{array}$ \\
\hline Global index of collocation & GIC & The geographic distinctness or overlap of two populations of fish. \\
\hline Number of spatial patches & $\mathrm{NoP}$ & $\begin{array}{l}\text { The geographic patchiness of fish populations. NoP depends on the threshold distance } \\
\text { separating two patches and is sensitive to the locations of high densities of fish. }\end{array}$ \\
\hline Positive area & $P A$ & $\begin{array}{l}\text { The area where fish of a species occur. } P A \text { is greatly increased when fish occur at low } \\
\text { densities over a large area. }\end{array}$ \\
\hline Spreading area & $S A$ & $\begin{array}{l}\text { A measure of the area occupied by the stock that takes into account variation in fish } \\
\text { density. } S A \text { equals } P A \text { when the population is evenly spread with a constant density. }\end{array}$ \\
\hline Equivalent area & $E A$ & $\begin{array}{l}\text { The area that would be covered by the population if all individuals occupied the same } \\
\text { area. Independent of the absolute abundance and sensitive to the highest density values. }\end{array}$ \\
\hline Microstructure index & $M I$ & $\begin{array}{l}\text { The fine-scale variability of the fish density surface. It measures the relative importance } \\
\text { of structural components having a scale smaller than the sample lag. } 0 \text { corresponds to a } \\
\text { very regular, well-structured density surface, and } 1 \text { to a highly irregular, poorly structured, } \\
\text { density surface. }\end{array}$ \\
\hline
\end{tabular}

There are many possibilities ranging from the present European "command and control" system, through regional councils and co-management, to rights-based management (MRAG et al. 2009). It is envisaged that the management body includes members of the fishing industry, politicians, non-governmental organisations, scientists, and other interested professionals such as economists and sociologists. This is in conformity with recommendations concerning an EAFM (EC 2001b; FAO 2003). A consequence of envisaging a body drawn from such a wide range of skills is that scientific results about the fishery should be expressible simply and, preferably, visually.

The top tier of objectives for managing a fishery are probably best decided by political processes outside the management body so that its time is not taken up with arguments among competing interests, e.g. for more fish to be harvested, or for more conservation. FAO (2003) offers suggestions for top-level objectives:

- keep harvested species within ecologically viable stock levels by avoiding overfishing and maintaining and optimizing long-term yields;

- maintain habitats and populations of non-retained (bycatch) species within ecologically viable levels;

- keep impact on the structure, processes and functions of the ecosystem at an acceptable level;

- maximize net revenues; and

- support regional employment.

Another possibility would be to achieve a significant reduction in the rate of biodiversity loss (Jennings 2005).

The top-level objectives have to be translated into operational objectives for the work of the fishery management body. The operational objectives are likely to have to deal with a wide range of fisheries impacts and, under an EAFM, should be directed towards achieving sustainability. Prioritisation of objectives is necessary to prevent an impractical proliferation of them (Jennings 2005). An example of an operational objective designed to meet the first political objective in the bulleted list above might be 'To maintain $10 \%$ of the stock at age 3 or older". Each operational objective should be directly addressable by scientific means. The trawl survey indicators (Tables 1 and 2) have obvious value for this although they are not intended to serve all possible operational objectives, such as those related to species other than fish in the ecosystem. Suggestions for this aspect are given below under 'Suitability of the trawl survey'.

\section{Selection of biological and spatial indicators}

Guidance on the selection of indicators for managing a fishery is provided by Jennings (2005), Rice and Rochet (2005), Rochet and Rice (2005), and other papers in the conference proceedings edited by Daan et al. (2005). Published studies of the performance of selected indicators in fished situations are also available (Piet and Jennings 2006). Spatial indices (Woillez et al. 2007; Woillez et al. 2009a) provide another way of looking at a fish stock and, since they depend on station-by-station catch rates, they are valuable for exposing information not used by composite indicators, as many biological indicators are.

The biological indicators listed in Table 1 relate to most key biological processes of a population including growth, condition, maturity, reproduction, abundance, and mortality. There are of course hundreds more indicators to choose from (Rochet and Trenkel 2003; Methratta and Link 2006). The first step in selecting indicators is the identification of fishing impacts most likely to compromise attainment of the operational objectives. The impacts are then prioritised according to severity and likelihood of occurrence, e.g. using the risk assessment methodology developed in Australia (Fletcher 2005). Next, 
state indicators relevant to impacted components of the ecosystem are selected, depending on resources (Jennings 2005) and the seasonal timing of the survey relative to seasonal biological processes. Several simulation studies concerned with the performance of ecological state indicators have been reported recently (Fulton et al. 2005; Hall et al. 2006; Methratta and Link 2006; Travers et al. 2006). Evaluation of possible management strategies (De Oliveira et al. 2008) based on indicators could be undertaken with further simulations using the ALADYM age-length-based model (Lembo et al. 2009), or the FLR system (Kell et al. 2007; Hillary 2009).

There are further technical considerations to apply when selecting biological indicators for fish stocks and ecosystems. In the context of trawl surveys, the suitability of the available surveys must be carefully considered for each indicator. Species that are poorly caught by the survey gear will occur infrequently in survey catches and are therefore likely to create a very noisy indicator series, see Trenkel and Cotter (2009) for more discussion. The season of the survey is especially important for indicators related to reproduction and growth (Cotter et al. 2009). Rice and Rochet (2005) argue that the number of indicators chosen should be minimal to prevent conflicting signals and arguments. Cotter et al. (2009) make a similar case based on the statistical dependence among many indicators. A high degree implies redundancy, possibly leading to overinterpretation of the various time series as well as unnecessary expense for collecting them. An example would be growth in length and bodily condition which both depend strongly on one factor, food supply. Dependence can also result from correlated sampling errors that mask or distort functional relationships among indicators. When this occurs, as it typically does when indicators are estimated using fish from the same hauls on a survey, there may be a case for cutting back on the number of indicators monitored.

\section{Selection of indicators of fishing pressure}

Commercial fishing pressure is not monitored by trawl surveys but is relevant to any EAFM (Jennings 2005). Less research attention has been given to indicators of fishing effort than to those of ecological state (Seijo and Caddy 2000; Link et al. 2002) but recent papers by Piet et al. (2007) and Hiddink et al. (2006) provide different perspectives on the pressures of commercial trawling effort. Ideally, the links between indicators of fishing pressure and ecological state will be well understood so that fishing can be managed in relation to properties of the ecosystem (Jennings 2005). Another good reason for having both types of indicator is to identify biological processes that can mimic the effects of high fishing effort. For example, short-lived species caught early in their life, such as red mullet in the Mediterranean and anchovy, can experience density-dependent changes of growth and natural mortality rates similar to that caused by increased fishing effort. Pressure indicators can be studied with similar statistical methods as state indicators, for example, those listed in Table 3. Also, canonical correlation analysis has been applied to try to identify the most important links between suites of pressure and state indicators, see Link et al. (2002) and Choi et al. (2005) for examples of such studies.

\section{Suitability of the trawl survey(s) for monitoring indicators}

For economic reasons, existing trawl surveys tend to serve many purposes (Ehrich et al. 2007) even though many were primarily intended to support or "tune" fish stock assessments based on models of the numbers of fish landed by commercial fleets. Special problems arise when trawl surveys are used to monitor indicators for species that were not of much interest before an EAFM was required. There can then be a mis-match of the survey area with the area occupied by the species, selective catching of different size classes, and other undesirable variations of survey catchability geographically or temporally, leading to biased estimation (Trenkel and Cotter 2009). Numerous other technical issues (Anonymous 2004, 2005) should also be considered before placing heavy reliance on the results of a survey, e.g. if a species is not consistently caught from year to year, or if availability of fish at several survey stations is likely to be affected by abundance of the stock due to contraction around favoured locations when numbers are low (Hutchings 1996). Generally, the precision of survey-based indicators for a stock declines significantly with declining abundance.

For these reasons, EAFM using survey-based models and indicator series might benefit from different emphases in the designs of pre-existing trawl surveys. Radical changes are unlikely to be acceptable because of the general wish in fisheries science communities to retain temporal continuity in survey results but deployment of additional fishing or sampling devices may well be feasible. Examples of supplementary sampling equipment successfully used on trawl surveys include a standardised 2-m beam trawl towed for $5 \mathrm{~min}$ at each station fished with the main gear (Callaway et al. 2002a,b), benthic grabs (Rees et al. 2006; Rees et al. 2008), acoustic systems (Everson et al. 1996; Greenstreet et al. 1997; Mackinson et al. 2004; Mackinson and van der Kooij 2006), and plankton collectors (Beaugrand 2005). Trawl surveys have also been used as wide-ranging platforms for observations of sea birds (Tasker et al. 1984) and marine mammals (Northridge and Mackay 2006). Special "distance sampling" statistical methods have been developed for these purposes (Buckland et al. 2004).

A survey might also be unsuitable for monitoring an indicator if its expected ability to distinguish a trend over time from measurement noise is low (Nicholson and Jennings 2004). Several methods for doing this are discussed below under "Statistical methods . . ." Increasing the frequency of surveys from annual to, say, twice-yearly, possibly with reduced numbers of stations being fished on each occasion to minimise extra costs, might be a helpful strategy for picking up and acting upon signals available from priority indicators earlier depending, of course, on whether radically rearranging survey schedules is feasible and on whether the cut-back surveys can provide sufficient precision for all the important tasks. Another significant consideration is whether valid results can be obtained in both seasons (Trenkel et al. 2004; Cotter et al. 2009).

Rotherham et al. (2007) provide guidance for those finding themselves with the challenge of designing a survey specifically to manage a fishery without relying on other data. Geographic variation may be important. In the Mediterranean, fishing fleets mostly work along the narrow continental shelves near the ports and, hence, a stock may show different levels 
Table 3. Methods used or developed during the FISBOAT project for integrating and interpreting indicator series.

\begin{tabular}{|c|c|c|c|}
\hline Task/Category & Method & Description and properties & Reference \\
\hline \multirow[t]{2}{*}{$\begin{array}{l}\text { Simulating population } \\
\text { dynamics }\end{array}$} & ALADYM & $\begin{array}{l}\text { An age-length based simulation model for predicting } \\
\text { the effects of different fishing pressures on a single } \\
\text { population of fish. }\end{array}$ & Lembo et al. 2009 \\
\hline & $\begin{array}{l}\text { Estimating indicators and refer- } \\
\text { ence points }\end{array}$ & A Monte Carlo approach using ALADYM & Lembo et al. 2009 \\
\hline \multirow[t]{4}{*}{$\begin{array}{l}\text { Indicator } \\
\text { methods }\end{array}$} & Intersection union test & $\begin{array}{l}\text { Estimates the direction of recent changes -up or } \\
\text { down- using the first and second derivatives of the } \\
\text { smoothed time-series. }\end{array}$ & Trenkel and Rochet 2008 \\
\hline & $\begin{array}{l}\text { Assessing the power to detect } \\
\text { future trends }\end{array}$ & Estimates the power to detect future, linear trends. & $\begin{array}{l}\text { Bogaards et al. (in Cotter } \\
\text { 2007) }\end{array}$ \\
\hline & $\begin{array}{l}\text { Statistical process control } \\
\text { (SPC) schemes }\end{array}$ & $\begin{array}{l}\text { Industrial quality control schemes, e.g. CUSUM, ap- } \\
\text { plied to monitor fishery and environmental qualities } \\
\text { derived from time series of indicators. }\end{array}$ & $\begin{array}{l}\text { Mesnil and Petitgas } \\
\text { 2009) }\end{array}$ \\
\hline & $\begin{array}{l}\text { Nonparametric statistical meth- } \\
\text { ods for assessing trends }\end{array}$ & $\begin{array}{l}\text { Statistical methods for assessing trends in fishery and } \\
\text { environmental indicators with minimal assumptions. }\end{array}$ & Cotter 2009 \\
\hline \multirow[t]{3}{*}{$\begin{array}{l}\text { Construction of multi- } \\
\text { variate indices }\end{array}$} & $\begin{array}{l}\text { Principal components analysis } \\
\text { (PCA) and biological indicators }\end{array}$ & $\begin{array}{l}\text { Represents the evolution of a stock, characterised by } \\
\text { many biological indicators, as a multivariate distance } \\
\text { from a reference centre of gravity. }\end{array}$ & Petitgas 2007 \\
\hline & $\begin{array}{l}\text { Multi-factorial analysis (MFA) } \\
\text { and spatial indicators }\end{array}$ & $\begin{array}{l}\text { Extends the PCA method to cases where the same } \\
\text { variables (spatial indicators) are measured for the } \\
\text { same individuals (e.g. stations) at different times. } \\
\text { Can summarise the spatial organisation of a species } \\
\text { through different age classes. }\end{array}$ & $\begin{array}{l}\text { Petitgas and Poulard } \\
2009\end{array}$ \\
\hline & $\begin{array}{l}\text { Min/Max autocorrelation fac- } \\
\text { tors (MAFs) and time continuity }\end{array}$ & $\begin{array}{l}\text { MAFs are linear combinations of indicator time se- } \\
\text { ries that are continuous in time. Can be used with } \\
\text { spatial indices to follow distribution of a fish popula- } \\
\text { tion over time. }\end{array}$ & Woillez et al. 2009b \\
\hline \multirow[t]{3}{*}{$\begin{array}{l}\text { Diagnosing stock status } \\
\text { from indicator series }\end{array}$} & $\begin{array}{l}\text { Combining trend signals using a } \\
\text { cause-effects table }\end{array}$ & $\begin{array}{l}\text { A simple, approach for causal interpretation of time } \\
\text { trends in different types of biological and fishery in- } \\
\text { dicators. }\end{array}$ & Trenkel et al. 2007a \\
\hline & A "traffic light" procedure & $\begin{array}{l}\text { Simple, visual traffic light table from the results of } \\
\text { CUSUM procedures applied to various indicator se- } \\
\text { ries. }\end{array}$ & Petitgas 2009 \\
\hline & $\begin{array}{l}\text { A multi-variate statistical proce- } \\
\text { dure }\end{array}$ & $\begin{array}{l}\text { PCA and related techniques for the results of } \\
\text { CUSUM procedures applied to the various indicator } \\
\text { series. }\end{array}$ & $\begin{array}{l}\text { Petitgas 2007; Petitgas } \\
\text { and Poulard } 2009\end{array}$ \\
\hline
\end{tabular}

of abundance and demographic structure over relatively short distances along these narrow stripes. As already mentioned, seasonal variation is very important for indicators of reproductive capacity, e.g. SSN, GSI, LaM50, AaM50 (Table 1), and of growth and condition, e.g. C, L25 (Table 1). Spatial indicators (Table 2) may also vary strongly with season and/or life stage depending on migrations, as observed for red mullet (Spedicato et al. 2007), and perhaps with mortality. If the season of a survey cannot be altered, the choice of indicators should be restricted to those that are compatible with the time of year.

\subsection{Data analysis}

The reference period and reference values or trend directions for indicators

Having planned and carried out surveys as part of an EAFM, criteria are needed for comparison with the resulting time series of indicators to decide whether the ecosystem is being adequately protected from the effects of fishing or not. Reference points are values chosen on best available information to help a management body to decide whether the level of an indicator signifies that a stock or an ecosystem is in a good state, or in a bad state needing corrective action. The points may be chosen to signal for example, "no impact", a precautionary "need for corrective action", or a limiting "need for extreme action" such as closure of the fishery. Deciding these values in advance of any problems and possibly without extensive experience of monitoring the ecosystem may prove difficult and subjective. Simulating the fishery under known conditions representing low and high fishing pressures combined with different levels of observation error could assist; the ALADYM model, possibly with a Monte Carlo approach (Table 3), and the FLR system (Kell et al. 2007) are two possible methods for doing this. Expert decision based on experience in other systems is another one (e.g. Link 2005) but simulation modelling may still be advisable to see whether 
unrealistic values are being considered. Reference points and directions are certainly matters to be negotiated with all interests represented on the fishery management body. Jennings (2005) discusses reference points in more detail, pointing out that hitting targets may be better policy than avoiding limits, and that reference directions (e.g. "towards improvement") may be easier to find and agree than absolute values or slopes.

Finding reference points or directions is often greatly assisted by knowledge of a period when fish stocks or the ecosystem were in an acceptable condition, probably at a time of low fishing effort, or before the fishery matured and yields per unit of effort started to decline substantially. Values or trends for each indicator may then be interpreted relative to this socalled "reference period" taking into account elementary facts about the biology and behaviour of the species (Table 3, causeeffects). In some cases, research results already permit convincing explanations of what is happening in the ecosystem, as for some groups of size-based (Shin et al. 2005) and population (Trenkel et al. 2007b) indicators.

\section{Statistical methods for evaluating changes in indicators}

Indicator series derived from fish surveys are likely to be affected by considerable sampling and measurement variance so a statistical approach to assessing compliance with pre-set reference points or directions is important. Several methods have been documented to assist comparisons:

- Recent trends are likely to be of most interest; they can be assessed from first and second derivatives of the smoothed series (Table 3, intersection-union test).

- The CUSUM method offers a sensitive method for checking whether fishery and environmental quality indicators are behaving as expected (Table 3, SPC method). A reference period is essential.

- Nonparametric statistical methods can be used to assess prevailing levels and overall trends without using models and with minimal assumptions, making them relatively objective and easy to explain (Table 3, nonparametric methods).

- Least squares linear models are often used but the assumption of linearity is likely to be unrealistic because environmental variables generally do not vary in straight lines. If not, serially correlated residuals and over-estimated precision and confidence result.

\section{Methods for combining indicator results}

Management of a fishery will probably need many indicators. Two problems ensue. One is how to understand collectively the many, possibly different signals about the stock and the ecosystem; the other is to recognise that results of some indicators are linked with results for others, either through functional or sampling dependences.

One approach is to form new composite indices from groups of individual indices. Principal components analysis (PCA) weights the different indices so that the weighted averages can be used as composites that are statistically independent (Link et al. 2002). The first two or three principal components - orthogonal axes through the data cloud - usually explain most of the variability and can be very helpful for understanding the signal from groups of correlated indicators. Indicators are composited into a multivariate distance from a central reference point so allowing a new perspective on evolution of the stock (Table 3 PCA method). Multi-factorial analysis (MFA) allows PCAs applied to each of several fishing stations to be combined. This can be useful for following changes in the prevailing spatial location of a species as individuals get older. Min/max autocorrelation factors (Table 3, MAF method) (Erzini et al. 2005; Woillez et al. 2009b) are used to combine a set of indices thought to be representative of a fish stock into components (factors) that present maximal continuity in time. The trends extracted do not allow reference periods to be defined because of their continuity. On the other hand, the continuity allows the status of the stock to be monitored in time (Woillez et al. 2007). Erzini et al. (2005) describe another multivariate technique, dynamic factor analysis, for modelling suites of indicator time series in terms of possible explanatory variables.

Another approach, to the problems of multiple indicators, is simpler and amounts to a preparation of a systematic diagnosis of changes in a stock from different individual signals. The cause-effects table (Table 3) attempts an interpretation of joint time trends in terms of underlying driving causes, which can be environmental or due to fishing (Trenkel et al. 2007b; Dambacher et al. 2009). A simple visual tabulation of results for groups of variables, possibly after transformation to CUSUMS, using red, orange, and green colouring to indicate perceived harm, insignificance, or benefit, respectively, to the stock and ecosystem is also available (Table 3), "traffic light", table (Halliday et al. 2001; Caddy 2002; DFO 2003; Petitgas 2009). It can reveal at a glance whether a stock might be in difficulty or not, though care is needed to recognise that strongly correlated indicators do not add to the weight of evidence just because they are all showing the same signal. A third diagnostic method again uses PCA but, in this approach, to summarise independent groups of indicators so as to assist understanding of the signals underlying them. See "multi-variate statistical" method (Table 3).

\section{Selection of a survey-based assessment method}

The CPUE-based models shown in Table 4 estimate relative abundances (rather than absolute numbers) of recruits and adults, total mortality $Z$, and other variables. These standard outputs are likely to be valued by fisheries biologists used to interpreting fish stock models and wishing to use them to complement indicator-based methods. The models could also estimate some indicators directly, e.g. $Z$ and age compositions. The estimates, if based on a model fitted to several years of results, would often vary more smoothly than estimates made directly from current results only, though this apparent advantage is of course dependent on the truth of the assumptions underlying the model. The modelling options for survey CPUEs include LENSUR for length-structured assessments, BREM for modelling biomass, and TSA, SURBA, or YCC for age-structured assessments (Table 4). There is the potential, therefore, for looking at stocks from the perspectives of length, 
Table 4. Fishery-independent assessment models employed in the FISBOAT project (Mesnil et al. 2009).

\begin{tabular}{lllll}
\hline Method & $\begin{array}{l}\text { Abbrev- } \\
\text { iation }\end{array}$ & Description and properties & References \\
\hline $\begin{array}{l}\text { Biomass random } \\
\text { effects model }\end{array}$ & BREM & $\begin{array}{l}\text { Relative biomass is modelled as a function of last year's biomass, a net growth co- } \\
\text { efficient incorporating growth and mortality, and annual recruitments. The growth } \\
\text { coefficient and recruitments are treated as random walks on the log scale. }\end{array}$ & Trenkel 2008 \\
\hline $\begin{array}{l}\text { Length structured } \\
\text { model }\end{array}$ & LENSUR & $\begin{array}{l}\text { Generates an artificial population in numbers by length class and time step, as } \\
\text { specified by a set of parameters. Model observations are derived from the operating } \\
\text { model in an observation model, and parameters are estimated by minimising the }\end{array}$ & $\begin{array}{l}\text { Skagen (in Cotter } \\
\text { deviation of the model observations from real observations. }\end{array}$ \\
\hline $\begin{array}{l}\text { Survey-based, age } \\
\text { structured model }\end{array}$ & SURBA & $\begin{array}{l}\text { Abundance at each age and year of a cohort is given by the recruiting abundance } \\
\text { of the relevant cohort modified by the cumulative effect of (separable) mortality } \\
\text { during its lifetime. Parameters are estimated by minimising the weighted sum-of- }\end{array}$ & et al. 2009) \\
squares of observed and estimated abundance indices. & \\
\hline $\begin{array}{l}\text { Time-series } \\
\text { analysis }\end{array}$ & TSA & $\begin{array}{l}\text { A state-space, random walk framework for modelling abundance-at-age indices } \\
\text { from a single survey. Fitting of parameters by Kalman filter. }\end{array}$ & Fryer (in Mesnil \\
Year-class & curve & YCC & $\begin{array}{l}\text { Estimates annual recruitments and total mortality, Z, by regressing log abundance } \\
\text { indices on age by year class. Also estimates relative catchabilities and residual }\end{array}$ & Cotter et al. 2007 \\
variances for different surveys. & & \\
\hline
\end{tabular}

biomass, abundance, and by age group. A comparison of the methods (except LENSUR) for simulated data is presented by Mesnil et al. (2009) and all were found to perform satisfactorily except when changes of catchability were introduced into the simulations. This weakness is to be expected for any trawlrelated assessment method. In addition to the models listed, Bayesian methods have also been applied (Porch et al. 2006).

\subsection{Management based on survey results}

Few fish surveys directly provide absolute estimates of numbers or weight of fish in a stock; they only provide relative estimates from year to year or place to place. This is because the catchability coefficient relating CPUE and population abundance locally is not known even approximately for trawl surveys, except in a few special situations (Tuck et al. 1997; Gjøsaeter et al. 2002). Indirect estimates of absolute quantities made in conjunction with commercial fishing data have been described (Korsbrekke et al. 2001) but are not widely in use. Relative estimates of quantity cannot be used to recommend absolute total allowable catches (TACs) that correspond to proposed levels of fishing mortality, $F$, as carried out annually to manage many stocks under the present European common fisheries policy (CFP). Many would feel that this is a fundamental flaw for survey-based management of fisheries. Counter arguments are presented in the discussion below. Furthermore, in the Mediterranean, fisheries have been regulated for many years already by control of effort and technical measures in relation to survey results.

Given only relative estimates, some sort of organised trial and error procedure, generally known as adaptive management (Walters 1986), becomes necessary for controlling fishing. All controls would have to be reviewed and re-negotiated on a regular basis in the light of monitoring results, the socio-economic factors relevant to the EAFM, and the high-level objectives of the management body. Jennings (2005) proposed that management should focus on fishing activities that are most likely to cause unsustainable impacts in the ecosystem; the relationships of current values of priority indicators to reference levels or trajectories provides guidance on the actions to take. Trenkel et al. (2007b) report just such an exercise. Surveybased assessments with abundance indices could also assist. Having decided whether there is a problem or not, the management body has to decide on appropriate harvest or effort control rules (HCR or ECR). HCRs and simulation testing of them have already been mentioned. Technical measures, e.g. mesh regulations, closed areas, by-catch rules, etc., are likely to form another important part of the management strategy. They may be particularly suited for controlling specific damage to the ecosystem, e.g. to reefs, or nursery areas. Trawl surveys, unfortunately, tend not to be helpful for this aspect of management; the areas may be untrawlable or there may be insufficient resources to focus fishing in the special regions.

\section{Discussion}

TACs intended to achieve target levels of fishing mortality $(F)$ became important for managing many international fisheries partly because they are easy to divide up by political agreement among nations, and partly because $F$ is a readily estimated parameter in virtual population analysis (VPA) and other stock assessment methods based on fishery-dependent data (Pope 1979). However, whether or not such TACs actually achieve control of the absolute numbers of fish in a stock, even if accurately implemented according to the recommendations of scientists, is now debatable. Only the total mortality $(Z)$, is directly estimable - from the decline in log numbers in each year class over time. $F$ must be estimated indirectly, usually by subtracting natural mortality, $M$, from $Z$, and, since $M$ is one of the hardest fishery parameters to estimate (Vetter 1988; Hewitt and Hoenig 2005; Gislason et al. 2008), significant bias in estimates of $F$, stock numbers, and thus, most importantly, the TACs would not be surprising (Rivard 1989; Lapointe and Peterman 1991; Mertz and Myers 1997), even if 
bias in the market sampling data and stock assessment models (Cotter et al. 2004) is somehow successfully avoided. Furthermore, TACs can fail to maintain a stock even if implemented perfectly (Kell et al. 2005). The TAC- $F$ system is now widely acknowledged to have a variety of disadvantages (Beverton 1998; Demaré 2006) and reform of the European common fisheries policy (CFP) has been actively discussed for some time (EC 2001b). It follows therefore that superiority of the supposedly absolute TAC management system over relative, surveybased methods cannot be safely presumed.

Most of the indicators and methods, listed in Tables 1 to 4, were applied to a variety of case studies considered under the FISBOAT project, ranging from cod in the Barents Sea to red mullet in the Mediterranean. The (unpublished) results varied with the stock and the survey. The pattern of variability and its time scale along the indicator series strongly influenced the detectability of trends and steps in the time series. Short series and missing values created additional problems. There were also difficulties in choosing reference periods as baselines for detecting change when stocks were heavily impacted by fishing throughout the survey series. For the same reason, some stocks showed no major changes in biological or spatial variables when tested with these methods. In conclusion, scientific judgements remain essential for the selection and interpretation of survey-based indicators and assessments, depending on the biology of the stocks, the ecosystem, and the history of fishing. Nevertheless, one clear advantage of applying a suite of methods, compared to the traditional focus on fish numbersat-age, is that a much broader understanding of the ecosystem can be gained. It is also an understanding to which fishers can usefully contribute as a result of their long experience at sea (Rochet et al. 2008), suggesting that unity within a management committee would be easier to attain. Another advantage of using an assortment of methods is that management is likely to be less affected by the weaknesses of any one, though this depends on the degree of independence between the data and models used.

Since so many fish stocks are now at low levels, the problem of choosing reference levels and directions for many indicators can, in many cases, safely be left as background research for the time-being. What is needed currently is not fine tuning of managerial measures but reversal of the trajectories of several important indicators, a process that is unlikely to be achieved within a year or two and which, it should be said, may not be detectable with confidence for even longer (Nicholson and Jennings 2004). In the meantime, reductions of fishing effort, reductions of discarding, and more stringent technical measures controlling mesh sizes and gear design are the simple tools that offer the best hope of higher, sustainable yields of fish under the present European common fisheries policy command-and-control management system. Possibly, political and economic changes to that system so as to give fishers more long-term investment in the resources they exploit would lead to a readier acceptance of the medicine by the fishing industry (Costello et al. 2008). The need for monitoring indicators and abundances would remain, though the customer for the work might change (in Europe, at least) from governments to industry.
Acknowledgements. This work was a contribution to the FISBOAT project funded by the European Commission and also supported by national fisheries agencies. The authors are grateful to the many other project participants who contributed to discussions.

\section{References}

Abella A., Belluscio A., Bertrand J., Carbonara P., Giordano D., Sbrana M., Zamboni A., 1999, Use of MEDITS trawl survey data and commercial fleet information for the assessment of some Mediterranean demersal resources. Aquat. Living Resour. 12, $155-166$.

Anonymous, 1986, Progress report 1985/1986 by ICES Statistician. Internat. Counc. Explor. Sea, Copenhagen, ICES CM 1986/D:19.

Anonymous, 2004, Report of the workshop on survey design and data analysis (WKSAD). Internat. Counc. Explor. Sea, ICES CM 2004/B:07, Ref. D.G. www.ices.dk/reports/FTC/2004/ WKSAD04.pdf

Anonymous, 2005, Report of the workshop on survey design and data analysis (WKSAD). Internat. Counc. Explor. Sea, Sète, France, ICES CM 2005/B:07. www.ices.dk/reports/FTC/2005/ WKSAD05.pdf

Anonymous, 2006, Report of the study group on survey trawl standardisation (SGSTS). Internat. Counc. Explor. Sea, ICES CM 2006/FTC:05, www.ices.dk/reports/FTC/2005/SGSTS05.pdf

Apostolaki P., Hillary R., 2009, Harvest control rules in the context of fishery-independent management of fish stocks. Aquat. Living Resour. 22, 217-224.

Armstrong M.J., Payne A.I.L., Cotter A.J.R., 2008, Contributions of the fishing industry to research through partnerships. In: Payne A.I.L., Cotter A.J.R., Potter T. (Eds.) Advances in fisheries science 50 years on from Beverton and Holt. Oxford, Blackwell Publishing, pp. 63-84.

Beaugrand G., 2005, Monitoring pelagic ecosystems using plankton indicators. ICES J. Mar. Sci. 62, 333-338.

Beverton R.J.H., 1998, Fish, fact and fantasy. Rev. Fish Biol. Fish. 8, 229-249.

Buckland S.T., Andersen D.R., Burnham K.P., Laake J.L., Borchers D.L., Thomas L. (Eds.), 2004, Advanced distance sampling. Oxford University Press.

Caddy J.F., 2002, Limit reference points, traffic lights, and holistic approaches to fisheries management with minimal stock assessment input. Fish. Res. 56, 133-137.

Callaway R., Alsvåg J., de Boois I., Cotter J., Ford A., Hinz H., Jennings S., Kröncke I., Lancaster J., Piet G., Prince P., Ehrich S., 2002a, Diversity and community structure of epibenthic invertebrates and fish in the North Sea. ICES J. Mar. Sci. 59, 1199-1214.

Callaway R., Jennings S., Lancaster J., Cotter J., 2002b, Mesh-size matters in epibenthic surveys. J. Mar. Biol. Assoc. UK 82, 1-8.

Choi J.S., Frank K.T., Petrie B.D., Leggett W.C., 2005, Integrated assessment of a large marine ecosystem: a case study of the devolution of the eastern Scotian shelf, Canada. Oceanogr. Mar. Biol. Ann. Rev. 43, 47.

Cook R.M., 1997, Stock trends in six North Sea stocks as revealed by an analysis of research vessel surveys. ICES J. Mar. Sci. 54, 924-933.

Costello C., Gaines S.D., Lynham J., 2008, Can catch shares prevent fisheries collapse? Science 321, 1678-1681.

Cotter A.J.R. (Ed.) 2007, Manual of indicators and methods for assessing fish stocks using only fishery-independent, survey-based information. ICES CM 2007/O:27. 
Cotter A., 2009, A selection of nonparametric statistical methods for assessing trends in trawl survey indicators as part of an ecosystem approach to fisheries management (EAFM). Aquat. Living Resour. 22, 173-185.

Cotter A.J.R., Burt L., Paxton C.G.M., Fernandez C., Buckland S.T., Pan J.-X., 2004, Are stock assessment methods too complicated? Fish Fish. 5, 235-254.

Cotter A.J.R., Mesnil B., Piet G., 2007, Estimating stock parameters from trawl CPUE-at-age series using year-class curves. ICES J. Mar. Sci. 64, 234-247.

Cotter A.J.R., Pilling G.M., 2007, Landings, logbooks and observer surveys: improving the protocols for sampling commercial fisheries. Fish Fish. 8, 123-152.

Cotter J., Mesnil B., Witthames P., Parker-Humphreys M., 2009, Notes on nine biological indicators estimable from trawl surveys with an illustrative assessment for North Sea cod. Aquat. Living Resour. 22, 135-153.

Daan N., Christensen V., Cury P.M. (Eds.), 2005, Introduction. Quantitative ecosystem indicators for fisheries management. ICES J. Mar. Sci. 62, 307-614.

Dambacher J.M., Gaughan D.J., Rochet M.-J., Rossignol P.A., Trenkel V.M., 2009, Qualitative modelling and indicators of exploited ecosystems. Fish Fish. 10, in press.

Daskalov G.M., 2008, Overfishing affects more than fish populations: a case of trophic cascades and regime shifts in the Black Sea. In: Payne A.I.L., Cotter A.J.R., Potter T. (Eds.) Advances in fisheries science 50 years on from Beverton and Holt. Oxford, Blackwell Publishing, pp. 418-433.

Daskalov G.M., Grishin A., Rodionov S., Mihneva V., 2007, Trophic cascades triggered by overfishing reveal possible mechanisms of ecosystem regime shifts. Proc. Nat. Acad. Sci. 104, 1051810523.

De Oliveira J.A.A., Kell L.T., Punt A.E., Roel B.A., Butterworth D.S., 2008, Managing without best predictions: the management strategy evaluation framework. In: Payne A.I.L., Cotter J., Potter T. (Eds.) Advances in fisheries science 50 years on from Beverton and Holt. Oxford, Blackwell Publishing, pp. 104-134.

Demaré W., 2006, Fisheries-based management and advice in Europe. In: Motos L., Wilson D.C. (Eds.) The knowledge base for fisheries management. Amsterdam, Elsevier, pp. 295-305.

DFO, 2003, State of the eastern Scotian shelf ecosystem. Dept. of Fisheries and Oceans, DFO Can. Scient. Adv. Secr. Ecosystem status report, 2003/4.

EC, 2001a, Elements of a strategy for the integration of environmental protection requirements into the Common fisheries policy. Brussels, $\operatorname{COM}(2001) 143$ final, http://eur-lex.europa.eu/ LexUriServ/LexUriServ.do?uri=COM:2001:0143:FIN:EN:PDF

EC, 2001b, Green paper on The future of the common fisheries policy. European Commission, Luxembourg, $\operatorname{COM}(2001) 135$ final, http://ec.europa.eu/fisheries/greenpaper/volume1_en.pdf

Ehrich S., Adlerstein S., Brockmann U., Floeter J., Garthe S., Hinz H., Kröncke I., Neumann H., Reiss H., Sell A.F., Stein M., Stelzenmuller V., Stransky C., Temming A., Wegner G., Zauke G.P., 2007, 20 years of the German small-scale bottom trawl survey (GSBTS): A review. Senck. Marit. 13.

Erzini K., Inejih C.A.O., Stobberup K.A., 2005, An application of two techniques for the analysis of short, multivariate non-stationary time-series of Mauritanian trawl survey data. ICES J. Mar. Sci. 62, 353-359.

Everson I., Bravington M., Goss C., 1996, A combined acoustic and trawl survey for efficiently estimating fish abundance. Fish. Res. 26, 75-91.
FAO, 2003, The ecosystem approach to fisheries. FAO Technical guidelines for responsible fisheries, 4.

Fletcher W.J., 2005, The application of qualitative risk assessment methodology to prioritize issues for fisheries management. ICES J. Mar. Sci. 62, 1576-1587.

Fulton E.A., Smith A.D.M., Johnson C.R., 2003, Effect of complexity on marine ecosystem models. Mar. Ecol. Prog. Ser. 253, 1-16.

Fulton E.A., Smith A.D.M., Punt A.E., 2005, Which ecological indicators can robustly detect effects of fishing? ICES J. Mar. Sci. 62, 540-551.

Garcia M., Cochrane K.L., 2005, Ecosystem approach to fisheries: a review of implementation guidelines. ICES J. Mar. Sci. 62, 311318.

Gislason H., Pope J.G., Rice J.C., Daan N., 2008, Co-existence in North Sea fish communities: implications for growth and natural mortality. ICES J. Mar. Sci. 65, 514-530.

Gjøsaeter H., Bogstad B., Tjelmeland S., 2002, Assessment methodology for Barents Sea capelin, Mallotus villosus (Müller). ICES J. Mar. Sci. 59, 1086-1095.

Greenstreet S.P.R., Tuck I.D., Grewar G.N., Armstrong E., Reid D.G., Wright P.J., 1997, An assessment of the acoustic survey technique, RoxAnn, as a means of mapping seabed habitat. ICES J. Mar. Sci. 54, 939-959.

Grieve C., Short K., 2007, Implementation of ecosystem-based management in marine capture fisheries. Global marine programme, WWF International, Av. du Mont-Blanc, 1196 Gland, Switzerland. www.panda.org/marine

Hall S.J., Collie J.S., Duplisea D.E., Jennings S., Bravington M., Link J., 2006, A length-based multispecies model for evaluating community responses to fishing. Can. J. Fish. Aquat. Sci. 63, 1344.

Halliday R.G., Fanning L.P., Mohn R.K., 2001, Use of the traffic light method in fishery management planning. CSAS Res. Doc. 2001.

Hewitt D.A., Hoenig J.M., 2005, Comparison of two approaches for estimating natural mortality based on longevity. Fish. Bull. 103, 433-437.

Hiddink J.G., Jennings S., Kaiser M.J., 2006, Indicators of the ecological impact of bottom-trawl disturbance on seabed communities. Ecosystems 9, 1190.

Hillary R., 2009, An introduction to FLR fisheries simulation tools. Aquat. Living Resour. 22, 225-232.

Hutchings J.A., 1996, Spatial and temporal variation in the density of northern cod and a review of hypotheses for the stock's collapse. Can. J. Fish. Aquat. Sci. 53, 943-962.

Jackson J.B.C., Kirby M.X., Berger W.H., et al., 2001, Historical overfishing and the recent collapse of coastal ecosystems. Science 293, 629-638.

Jennings S., 2005, Indicators to support an ecosystem approach to fisheries. Fish Fish. 6, 212-232.

Jennings S., Kaiser M.J., 1998, The effects of fishing on marine ecosystems. Adv. Mar. Biol. 34, 201-352.

Kell L.T., Mosqueira I., Grosjean P., Fromentin J.M., Garcia D., Hillary R., Jardim E., Mardle S., Pastoors M., Poos J.J., Scott F., Scott R.D., 2007, FLR: an open-source framework for the evaluation and development of management strategies. ICES J. Mar. Sci. 64, 640-646.

Kell L.T., Pilling G.M., Kirkwood G.P., Pastoors M., Mesnil B., Korsbrekke K., Abaunza P., Aps R., Biseau A., Kunzlik P., Needle C., Roel B.A., Ulrich-Rescan C., 2005, An evaluation of the implicit management procedure used for some ICES roundfish stocks. ICES J. Mar. Sci. 62, 750-759.

Kimura D.K., Somerton D.A., 2006, Review of statistical aspects of survey sampling for marine fisheries. Rev. Fish. Sci. 14, 245-283. 
Korsbrekke K., Mehl S., Nakken O., Pennington M., 2001, A surveybased assessment of the Northeast Arctic cod stock. ICES J. Mar. Sci. 58, 763-769.

Lack M., 2004, Ecosystem-based management in marine capture fisheries: a review of selected tools used in australian fisheries. WWF-Australia, PO Box 528, Sydney, NSW 2001 publications@wwf.org.au

Lapointe M.F., Peterman R.M., 1991, Spurious correlations between fish recruitment and environmental factors due to errors in the natural mortality rate used in virtual population analysis (VPA). ICES J. Mar. Sci. 48, 219-228.

Lembo G., Abella A., Fiorentino F., Martino S., Spedicato M.T., 2009, ALADYM: an age- and length-based single species simulator for exploring alternative management strategies. Aquat. Living Resour. 22, 233-241.

Link J.S., 2005, Translating ecosystem indicators into decision criteria. ICES J. Mar. Sci. 62, 569-576.

Link J.S., Brodziak J.K.T., Edwards S.F., Overholtz W.J., Mountain D.G., Jossi J.W., Smith T.D., Fogarty M.J., 2002, Marine ecosystem assessment in a fisheries management context. Can. J. Fish. Aquat. Sci. 59, 1429-1440.

Mackinson S., Freeman S., Flatt R., Meadows B., 2004, Improved acoustic surveys that save time and money: Integrating fisheries and ground-discrimination acoustic technologies. J. Exp. Mar. Biol. Ecol. 305, 129.

Mackinson S., van der Kooij J., 2006, Perceptions of fish distribution, abundance and behaviour: observations revealed by alternative survey strategies made by scientific and fishing vessels. Fish. Res. 81, 306.

Marchal P., Andersen B., Caillart B., Eigaard O., Guyader O., Hovgaard H., Iriondo A., Le Fur F., Sacchi J., Santurtun M., 2007, Impact of technological creep on fishing effort and fishing mortality, for a selection of European fleets. ICES J. Mar. Sci. 64, 192-209.

Marchal P., Ulrich C., Korsbrekke K., Pastoors M., Rackham B., 2003, Annual trends in catchability and fish stock assessments. Sci. Mar. 67 (Suppl. 1), 63-73.

McShane P.E., Broadhurst M.K., Williams A., 2007, Keeping watch on the unwatchable: technological solutions for the problems generated by ecosystem-based management. Fish Fish. 8, 153161.

Mertz G., Myers R.A., 1997, Influence of errors in natural mortality estimates in cohort analysis. Can. J. Fish. Aquat. Sci. 54, 16081612.

Mesnil B., Cotter J., Fryer R.J., Needle C.L., Trenkel V.M., 2009, A review of fishery-independent assessment models, and initial evaluation based on simulated data. Aquat. Living Resour. 22, 207-216.

Mesnil B., Petitgas P., 2009, Detection of changes in time series of indicators using CUSUM control charts. Aquat. Living Resour. 22, 187-192.

Methratta E.T., Link J.S., 2006, Evaluation of quantitative indicators for marine fish communities. Ecol. Indicators 6, 575.

Mitson R.B., 1995, Underwater noise of research vessels - review and recommendations. ICES Coop. Res. Rep. 209.

Mitson R.B., Knudsen H.P., 2003, Causes and effects of underwater noise on fish abundance estimation. Aquat. Living Resour. 16, 255-263.

Motos L., Wilson D.C., 2006, The knowledge base for fisheries management. Elsevier.

MRAG, IFM, CEFAS, Tecnalia A., PoIEM, 2009, An analysis of existing rights based management (RBM) instruments in Member States and on setting up best practices in the EU. MRAG Ltd., London, FISH/2007/03.
Mullon C., Fréon P., Cury P., 2005, The dynamics of collapse in world fisheries. Fish Fish. 6, 111-120.

Myers R.A., Worm B., 2003, Rapid worldwide depletion of predatory fish communities. Nature 423, 280-283.

Nicholson M.D., Jennings S., 2004, Testing candidate indicators to support ecosystem-based management: the power of monitoring surveys to detect temporal trends in fish community metrics. ICES J. Mar. Sci. 61, 35-42.

Northridge S., Mackay A., 2006, United Kingdom progress report on cetacean research, April 2005 to May 2006, with statistical data for the calendar year 2005. Sea Mammal Res. Unit, University of St. Andrews, Scotland http://iwcoffice.org/_documents/sci_com/ 2006progreports/SC-58-ProgRepUK.pdf

Pauly D., Christensen V., Guénette S., Pitcher T.J., Sumaila R., Walters C., Watson R., Zeller D., 2002, Towards sustainability in world fisheries. Nature 418, 689-695.

Petitgas P., 2007, Principal components analysis (PCA) and biological indicators. ICES CM 2007/O:27, pp. 122-125.

Petitgas P., 2009, The CUSUM out-of-control table to monitor changes in fish stock status using many indicators. Aquat. Living Resour. 22, 201-206.

Petitgas P., Poulard J.C., 2009, A multivariate indicator to monitor changes in spatial patterns of age-structured fish populations. Aquat. Living Resour. 22, 165-171.

Piet G., Jennings S., 2006, Response of potential fish community indicators to fishing. ICES J. Mar. Sci. 62, 214-225.

Piet G., Quirijns F.J., Robinson L., Greenstreet S.P.R., 2007, Potential pressure indicators for fishing, and their data requirements. ICES J. Mar. Sci. 64, 110-121.

Pope J.G., 1979, Population dynamics and management: current status and future trends. Invest. Pesq. 43, 199-221.

Porch C.E., Eklund A.M., Scott G.P., 2006, A catch-free stock assessment model with application to goliath grouper (Epinephelus itajara) off southern Florida. Fish. Bull. 104, 89-101.

Rees H.L., Boyd S.E., Schratzberger M., Murray L.A., 2006, Role of benthic indicators in regulating human activities at sea. Environ. Sci. Policy 9, 496-508.

Rees H.L., Ellis J.R., Hiscock K., Boyd S.E., Schratzberger M., 2008, Benthic communities, ecosystems and fisheries. In: Payne A.I.L., Cotter A.J.R., Potter T. (Eds.) Advances in fisheries science 50 years on from Beverton and Holt. Oxford, Blackwell Publishing.

Rice J.C., Rochet M.-J., 2005, A framework for selecting a suite of indicators for fisheries management. ICES J. Mar. Sci. 62, 516527.

Rice J.C., Trujillo V., Jennings S., Hylland K., Hagstrom O., Astudillo A., Jensen J.N., 2005, Guidance on the application of the ecosystem approach to management of human activities in the European marine environment. ICES Coop. Res. Rep., 273, 22pp.

Rivard D., 1989, Overview of the systematic, structural, and sampling errors in cohort analysis. Am. Fish. Soc. Symp. 6, 49-65.

Rochet M.-J., Prigent M., Bertrand J.A., Carpentier A., Coppin F., Delpech J.-P., Fontenelle G., Foucher E., Mahé K., Rostiaux E., Trenkel V.M., 2008, Ecosystem trends: evidence for agreement between fishers' perceptions and scientific information. ICES J. Mar. Sci. 65, 1057-1068.

Rochet M.-J., Rice J.C., 2005, Do explicit criteria help in selecting indicators for ecosystem-based fisheries management? ICES J. Mar. Sci. 62, 528-539.

Rochet M.-J., Trenkel V.M., 2003, Which community indicators can measure the impact of fishing? A review and proposals. Can. J. Fish. Aquat. Sci. 60, 86-99. 
Rochet M.-J., Trenkel V.M., 2009, Why and how could indicators be used in an ecosystem approach to fisheries management? In: Beamish R.J., Rothschild B.J. (Eds.) The future of fisheries science in North America. Springer, pp. 209-226.

Rose G.A., Kulka D.W., 1999, Hyperaggregation of fish and fisheries: how catch-per-unit-effort increased as the northern cod (Gadus morhua) declined. Can. J. Fish. Aquat. Sci. 56, 118-127.

Rotherham D., Underwood A.J., Chapman M.G., Gray C.A., 2007, A strategy for developing scientific sampling tools for fisheryindependent surveys of estuarine fish in New South Wales, Australia. ICES J. Mar. Sci. 64, 1512-1516.

Seijo J.C., Caddy J.F., 2000, Uncertainty in bio-economic reference points and indicators of marine fisheries. Mar. Freshw. Res. 51.

Shin Y.-J., Rochet M.-J., Jennings S., Field J.G., Gislason H., 2005, Using size-based indicators to evaluate the ecosystem effects of fishing. ICES J. Mar. Sci. 62, 384-396.

Spedicato M.T., Woillez M., Rivoirard J., Petitgas P., Carbonara P., Lembo G., 2007, Usefulness of the spatial indices to define the distribution pattern of key life stages: an application to the red mullet (Mullus barbatus) population in the south Tyrrhenian Sea. ICES CM 2007/O.

Tasker M.L., Hope Jones P., Dixon T., Blake B.F., 1984, Counting seabirds at sea from ships: a review of methods employed and a suggestion for a standardized approach. The Auk 101, 567-577.

Travers M., Shin Y.J., Shannon L., Cury P., 2006, Simulating and testing the sensitivity of ecosystem-based indicators to fishing in the southern Benguela ecosystem. Can. J. Fish. Aquat. Sci. 63, 943-956.

Trenkel V.M., 2008, A two-stage biomass random effects model for stock assessment without catches: what can be estimated using only biomass survey indices? Can. J. Fish. Aquat. Sci. 65, 10241035.

Trenkel V.M., Cotter A.J.R., 2009, Choosing survey time series for populations as part of an ecosystem approach to fishery management. Aquat. Living Resour. 22, 121-126.

Trenkel V.M., Pinnegar J.K., Rochet M.-J., Rackham B., 2004, Different survey designs provide similar pictures of community structure but not of individual fish populations. ICES J. Mar. Sci. 61, 351-362.

Trenkel V.M., Rochet M.-J., 2008, Intersection-union tests for characterising recent changes in smoothed indicator time series. Ecol. Indicators 9, 732-739.

Trenkel V.M., Rochet M.-J., Mesnil B., 2007a, Combining trend signals using a cause-effects table. ICES CM 2007/O:27 FISBOAT final report, pp. sect. 5.5.1.

Trenkel V.M., Rochet M.J., Mesnil B., 2007b, From model-based prescriptive advice to indicator-based interactive advice. ICES J. Mar. Sci. 64, 768-774.

Tuck I.D., Chapman C.J., Atkinson R.J.A., Bailey N., Smith R.S.M., 1997, A comparison of methods for stock assessment of the Norway lobster, Nephrops norvegicus, in the Firth of Clyde. Fish. Res. 32, 89-100.

Vetter E.F., 1988, Estimation of natural mortality in fish stocks: a review. Fish. Bull. 86, 25-43.

Walters C., 1986, Adaptive management of renewable resources. MacMillan Publishing Co., New York.

Ward T., Tarte D., Hegerl E., Short K., 2006, Ecosystem-based management of marine fisheries-policy proposals and operational guidance for ecosystem-based management of marine capture fisheries. World Wide Fund for Nature Australia www.panda.org

Woillez M., Poulard J.C., Rivoirard J., Petitgas P., Bez N., 2007, Indices for capturing spatial patterns and their evolution in time, with application to European hake (Merluccius merluccius) in the Bay of Biscay. ICES J. Mar. Sci. 64, 537-550.

Woillez M., Rivoirard J., Petigas P., 2009a, Notes on survey-based spatial indicators for monitoring fish populations. Aquat. Living Resour. 22, 155-164.

Woillez M., Rivoirard J., Petitgas P., 2009b, Using min/max autocorrelation factors of survey-based indicators to follow the evolution of fish stocks in time. Aquat. Living Resour. 22, 193-200. 